\title{
CHICHIMECAS NÓMADAS Y BÁRBAROS: IMAGEN Y DISCURSO EN LOS LIBROS DE TEXTO GRATUITOS DE HISTORIA, 1960-1996
}

\author{
Jenny Zapata de la Cruz*
}

\section{Resumen}

El objeto-sujeto de análisis de este artículo es el discurso escrito y visual sobre los chichimecas en los libros de texto gratuitos de historia para tercero, cuarto, quinto y sexto grados de primaria, editados por la Secretaría de Educación Pública, con el propósito de mostrar cómo mantienen y defienden el discurso colonizante que señala al indígena chichimeca como salvaje, desaparecido por sus prácticas nómadas, homogeneizando los diversos grupos chichimecas; estas visiones se conectan con el paradigma decimonónico de "evolución", concepto centrado en el de "civilización", que ha permeado la mentalidad mestiza de los siglos $x x$ y XXI, instituyendo un prototipo inverosímil de los chichimecas en el México contemporáneo. Para este fin se tomarán como muestra ediciones de 1960 a 1996.

Palabras clave: indígenas, chichimecas, civilización.

\section{Abstract}

The object-subjects of analysis is about the written and visual discourse of chichimecas in the elementary history textbooks from third, fourth, fifth, and sixth grades. They were published by the Secretaría de Educación Pública, and we show how these books maintain, and defend the colonizing discourse which points to indigenous chichimecas such as a wild indian who have disappeared by their nomadic practices. This vision is connected with the nineteenth-century paradigm of "evolution", concept focused with "civilization" which has pervaded the mestizo mindset of the $x x$ and $x x \mathrm{I}$ century. It creates

\footnotetext{
* División de Ciencias Sociales y Humanidades, Universidad de Guanajuato.
} 
an unlikely prototype of chichimecas in the contemporary mexican society. It will be shown some editions of 1960 and 1996 as samples.

Keywords: indigene, chichimecas, civilization.

\section{Introducción}

La imagen de los indígenas chichimecas, ${ }^{1}$ como una sociedad atrasada, pobre, salvaje, sanguinaria, caníbal, aguerrida, cruel y dispersa en lo que hoy se reconoce como la región del centro-occidente y norte de México, no es exclusiva de los siglos XIX y XX, se fue construyendo a través de las crónicas o relatos de los conquistadores españoles y misioneros que buscaban justificar y legalizar la conquista territorial y humana, tal como se encuentra en el tratado que redacta fray Guillermo de Santa María, ${ }^{2}$ entre 1575 y 1580: Guerra de los chichimecas. Según Alberto Carrillo, ${ }^{3}$ existen otras obras relacionadas con el tema: una del teólogo franciscano Juan Focher, ${ }^{4}$ editada por el humanista y teólogo fray Diego de Valadés, y dos más que conciernen a la guerra chichimeca, ${ }^{5}$ escritas por el teólogo Hernando Ortiz de Hinojosa, y por el jurista Fulgencio de Vique, que narran las acciones violentas de los indígenas. Aparentemente, sus escritos pretendían explicar o describir únicamente las prácticas culturales e integrar a estos grupos al mundo civilizado europeo por medio de la religión católica, pero detrás de esta intención se desarrollaban acciones políticas y militares de exterminio.

Estos relatos, que cuentan y reconstruyen la supuesta bestialidad de los chichimecas -como bien expone Pedro Tomé-, son tan crudos que "un

1 De acuerdo con los datos del Atlas de los pueblos indígenas de México, CDI (2014), los actuales chichimecas se ubican en los estados de Querétaro, de etnia pame-chichimeca; en Guanajuato, los chichimecas-jonaz, y San Luis Potosí, chichimecas-jonaz y pames.

2 Se ha pensado que es Gonzalo de las Casas quien escribió la Guerra de los chichimecas, sin embargo, Alberto Carrillo Cázeres ha comprendido, a través de su trabajo paleográfico, que fue el fraile agustino Guillermo de Santa María. Esta afirmación la hace Pedro Tomé Martín en el preámbulo de la obra Guerra de los chichimecas (México 1575-Zirosto 1580), p. 21.

3 Carrillo Cázares, "Estudio introductorio" a Guerra de los chichimecas, p. 30.

4 La obra se llama Itinerario del misionero de América.

5 Tomé Martín, "Prólogo" a Guerra de los chichimecas, p. 30. 
lector europeo de la época difícilmente podría evitar sentir náuseas al leerlo, odiar a tan bárbaras gentes y pedir a sus autoridades que las extermine". ${ }^{6}$ Y cómo no solicitar su exterminio si la Guerra de los chichimecas México 1575-Zirosto 1580) expone matanzas crueles y una vida antimoral, llena de violencia y prácticas sociales inhumanas, no aceptable para los ojos del dios europeo. ${ }^{7}$ Este discurso sin duda sigue vigente ${ }^{8}$ en el imaginario colectivo mestizo, el cual justifica toda acción para borrar a los pocos sobrevivientes.

No hay duda de que durante la conquista y la colonia fue práctica común de los europeos eliminar todo lo que estuviera en contra de la idea de civilización, la moral católica y sus intereses económicos y políticos. Este aspecto lo ha reflexionado Norbert Elías en El proceso de la civilización: Investigaciones sociogenéticas y psicogenéticas, en el que explica: "La sociedad europea occidental llevó a cabo sus guerras coloniales y expansivas en nombre de la cruz durante la Edad Media, como más tarde lo hará en nombre de la civilización". ${ }^{9}$ En este sentido, Emanuele Amodio abordó el tema del otro en la obra Formas de la alteridad, en la cual reflexiona sobre Colón y el encuentro con los indígenas del "nuevo mundo". Para Amodio la religión católica del que "descubre" marca la frontera entre lo "normal" y lo "anómalo":

Es decir, que los indígenas son incluidos en la categoría de las "disformidades", por el simple hecho de no tener religión; de hecho, la humanidad se caracteriza por ser cristiana, los que no lo son no son humanos. De cualquier manera estos "monstruos" culturales difieren de los monstruos vegetales y animales: pueden adquirir humanidad convirtiéndose al catolicismo. ${ }^{10}$

6 Tomé Martín, "Prólogo" a Guerra de los chichimecas, p. 13.

7 En el imaginario del que construye está: el otro y se ve a sí mismo como: nosotros, el europeo que asimila lo diferente a él, define al otro a partir de su carga cultural y sus necesidades sociales, respecto a esto, Amodio ha analizado estas categorías y explica que: "el otro considerado "monstruo", anormal frente a nuestra normalidad, permite la constitución del nos y el proceso se puede realizar justamente por asimilación posible". El reconocimiento del otro como semejante produce la base identificatoria que permite la constitución radical de la diferencia y la oposición a nosotros", Amodio Emanuele, Formas de la alteridad..., p. 21. 8 Es vigente en la dinámica de la construcción del otro.

9 Elías, El proceso de la civilización, p. 130.

10 Amodio Emanuele, op. cit., pp. 52-53. 


\section{Y en los libros de la Secretaría de Educación Pública...}

La construcción descriptiva de los chichimecas durante la conquista ha permanecido en la memoria de mestizos e indígenas, ${ }^{11}$ persistencia que se debe, además, a las narrativas orales, y a lo escrito y exhibido en los libros oficiales distribuidos por la Secretaría de Educación Pública (SEP), nivel primaria, desde la década de los sesenta, los cuales han insistido en explicar la existencia nómada y cultural de los chichimecas en las tierras denominadas "Aridoamérica" como práctica incivilizada. El prototipo del indio chichimeca sanguinario y salvaje, ${ }^{12}$ desarrollado en la Colonia, se entreteje con el análisis positivista y evolucionista de mediados del siglo XIX, que generalizó y diluyó la diversidad indígena del territorio nacional: "todos los indios son iguales", que, junto con el auxilio de estudios antropológicos se forja el discurso del indio flojo, borracho, ratero, servil, falto de pasiones e incivilizado -avalado por estudios antropométricos hechos a indígenas-. En este sentido, la ciencia justificó, en pos de la civilidad y la modernidad del espíritu decimonónico, la exclusión de los indígenas de este ideal. La disertación desarrollada por Francisco Pimentel en 1864 se basa en comparar las civilizaciones antiguas de Europa con las culturas de Mesoamérica, a las que clasifica en "civilizaciones avanzadas" e "indios en estado salvaje" (división que persistirá en los libros oficiales de la SEP para educación primaria ${ }^{13}$ en la segunda mitad del siglo xx). Para Pimentel, la lengua determina la personalidad: "el idioma pinta el carácter de un pueblo; encontraremos en las lenguas de los indios señales evidentes de su servilismo". ${ }^{14}$

11 Se han hecho entrevistas entre los chichimecas de San Luis de la Paz, Guanajuato, que muestran muchas características negativas atribuidas por los actuales habitantes a sus antepasados (entrevistas realizadas de 2008 a 2013).

12 Francisco Pimentel, en el siglo XIX, afirmaba: "cuando los españoles conquistaron a México, no encontraron en las provincias del Norte más que tribus errantes poco numerosas, y que ocupaban extensos terrenos. Todavía quedan restos de algunas tribus, y sus individuos se hallan completamente en estado salvaje, tal como los sérís en Sonora y los apaches en Chihuahua. Estos últimos penetran hasta el interior del país, hasta cerca de Zacatecas, asesinando sin piedad á cuanto encuentran. El principal objeto que tienen los indios bárbaros en sus incursiones, es robar el ganado caballar y mular. En lo único que han adelantado los salvajes del Norte, después de la Independencia, es en el uso y manejo de armas de fuego", en Memoria sobre las causas..., pp. 120-121.

13 Esta idea aparece de las ediciones de 1960 hasta las de 1971 y se retoma en las ediciones de 1992-1994, en los libros de tercero a quinto años de historia.

14 Pimentel, Memoria sobre las causas..., p. 82. 
Esta tendencia comparativa que clasifica a los indígenas como incivilizados, y, que además, "todos son iguales", responde a la necesidad de fijar la idea de civilidad y progreso, y los indígenas del siglo XIX no representaban el modelo que se requería para estar en el mundo de lo que se entendía por "civilizado". Los estudios antropológicos no tendían a la integración sino a la segregación y reformulaban al otro a partir de lo conocido, lo parecido al mundo europeo; luego, aquellos que no encajaban en el discurso occidental eran excluidos o eliminados. La idea del hombre bárbaro causa un malestar, incomodidad o repugnancia en el hombre civilizado; son las sensaciones de los prejuicios, como explican Nobert Elías y Emanuele Amodio. ${ }^{15}$ La idea de civilización en los libros de la SEP está vinculada con el comportamiento social, la decencia, la moral, los buenos modales, de los cuales - de acuerdo con el imaginario de los mexicanos- los indígenas chichimecas carecían (o carecen).

El siglo $\mathrm{xx}$ no va a alejarse de esa arquitectura del otro. El "redescubrimiento" de los indígenas después de la Revolución mexicana da pie a otras categorías de pensamiento, pues "el indoiberismo y el panamericanismo habían vinculado la noción de ciudanía moderna a las ideas de mestizaje racial y cultural", ${ }^{16}$ conceptos que se aceptan como la base de políticas educativas de la asimilación del indio oprimido, explotado, saqueado, pero también considerado como atrasado en cuanto a sus raíces culturales. Dicha asimilación y restauración, por el abandono de los gobiernos anteriores, se da o se ejecuta a través de la educación y la enseñanza del castellano; el pueblo progresista, revolucionario, debe estar sano, tener una ideología de nación y, por tanto, compartir una misma cultura, una misma lengua. Manuel Gamio expresa en su obra Forjando Patria que esta incapacidad del "indio" para integrarse a la civilización es el resultado de años de colonización y de la opresión sufrida durante el siglo XIX. Para Gamio, habría una sola nación, una sola patria, si los indígenas se acoplaran a la cultura occidental, y esto soló sería posible por medio de la educación. ${ }^{17}$ Vasconcelos es otro representante de la idea de cultura única:

15 Elías, El proceso de la civilización..., p. 136; Amodio, Formas de la alteridad, construcción y difusión de la imagen del indio americano en Europa durante el primer siglo de la conquista de América, pp. 21 y 112. 16 Urías Horcasitas, Historias secretas del racismo en México, p. 16.

17 Expresa Gamio: "sucede que determinados antecedentes históricos, y especialísimas condiciones sociales, biológicas, geográficas, etc., del medio en que vive lo han hecho hasta 
la raza cósmica, mestiza. Vicente Lombardo Toledano pensaba que el atraso de México se debía a los indígenas, a su resistencia a hablar español, a la continuidad de sus prácticas sociales y económicas antimodernas; entonces, si éstos se homogeneizaban por la vía de la lengua dominante, y si se les enseñaban actividades económicas modernas, disminuirían sus condiciones de pobreza y dejarían de ser el factor de atraso del país. ${ }^{18}$

Es claro que existe un vínculo ${ }^{19}$ entre la crónica de la Conquista española, el proceso científico antropológico segregacionista del siglo XIX y la asimilación del siglo xx: los tres tienden al ideal de una sociedad moderna y civilizada; por ende, se aspira a un México civilizado y moderno en su infraestructura económica y social; ideal de nación a la cual los indígenas no pertenecían por incultos y por su producción “comunitaria”, rudimentaria. Era necesario diseñar la política pública que acabara con el atraso y lograra la inclusión de quienes por siglos habían sido segregados; así, se decide rehacer la Secretaría de Instrucción Pública y Bellas Artes -nacida en 1905 y desaparecida en 1917-. En 1921 surge la Secretaría de Educación Pública, encargada de ejecutar estos proyectos civilizatorios y modernizantes, como lo fueron las misiones culturales itinerantes -después permanentes- que englobaban el quehacery la ideología redentora del Estado posrevolucionario, que encontraba en los campesinos mestizos e indígenas comportamientos nocivos para la patria: "Las Misiones viajeras de este tipo que se describen en este libro y de las Misiones permanentes de función civilizadora [...] -lo creemos sinceramente- [serán] la transformación social indispensable en México para la incorporación de las comunidades rurales a la vida civilizada, particularmente de las masas indígenas". ${ }^{20}$

hoy inepto para recibir y asimilar la cultura de origen europeo. Si el peso abrumador de los antecedentes históricos desaparece, que desaparecerá cuando el indio no recuerde ya los tres siglos de vejaciones coloniales y los cien años de vejaciones independentistas que gravitan sobre él; si deja de considerarse, como hoy lo hace, zoológicamente inferior al blanco; si mejoran su alimentación, su indumentaria, su educación y sus esparcimientos, el indio abrazará la cultura contemporánea al igual que el individuo de cualquier raza". Gamio, Forjando patria, pp. 38-39.

18 Véase Lombardo Toledano, El problema del indio.

19 Un lazo que no es homogéneo, sino que la ideología de la civilización se reconfigura de acuerdo con las circunstancias y las necesidades de cada época.

20 SEP, Las misiones culturales, p. 8. 
Este interés de civilizar, sanar e inculcar "otra" moral y civismo para barrer el analfabetismo -que significa falta de civilización- se confecciona a través de las políticas educativas del Estado. Este ideal se refleja en los contenidos e imágenes de los libros de texto gratuitos, proyecto de Jaime Torres Bodet en 1944, y que opera a partir de 1959 con la creación de la Comisión Nacional de los Libros de Texto Gratuitos (Conaliteg). El proyecto tiene la intención de lograr la integridad nacional e infundir la modernización, la obediencia y el respeto a la patria.

El primer libro de educación primaria de historia data de 1960, en cuya portada se muestra a los héroes de la Independencia de México; le sucede la edición de 1962 -se hicieron reimpresiones en 1964 y 1971- en la portada aparece "La Patria", obra artística de Jorge González Camarena, que la propia Conaliteg describe como "una mujer de tez morena, rasgos indígenas y mirada valerosa que apoyada en la agricultura, la industria y la cultura -simbolizadas en las imágenes del escudo y la bandera nacionales, un libro y diversos productos de la tierra y la industria-", 21 sintetiza el ideal de la nación posrevolucionaria del mestizaje y la eliminación del indígena chichimeca, obra icónica de los ideales modernizadores de la época; de manera indirecta los libros de texto buscarán borrar a los indígenas vivos que causan vergüenza y reflejan la cultura primitiva (entre ellos, especialmente, los chichimecas).

Para demostrar lo anterior, analizaremos varios libros de texto gratuitos de la materia de historia (que fueron apareciendo con diferentes nombres) para tercero, cuarto, quinto y sexto años de educación primaria, a partir de la década de los sesenta hasta la de los noventa. ${ }^{22}$

Evidenciaremos cómo estos textos hacen alusión al pasado glorioso de las grandes civilizaciones prehispánicas: azteca, tolteca, maya, mixteca-zapoteca,

21 Conaliteg-SEP, Historia, s/p. http://www.conaliteg.gob.mx/index.php/historia

22 Durante las décadas, partiendo de los setenta hasta inicios de los noventa fueron modificados los contenidos de los libros de texto; en una etapa, incluso desaparecieron las asignaturas de historia, geografía, civismo y lengua nacional; posteriormente, reaparecen los libros de ciencias sociales. Iniciada la reforma educativa, en el gobierno de Carlos Salinas de Gortari, se retomaron las disciplinas de historia, civismo y geografía. Por ello, a partir de la edición de 1971 no volveremos a revisar otro libro de historia (salvo la monografía del estado de Guanajuato de 1982) hasta la edición de 1992, cuando se retoma la historia como materia de estudio desde cuarto a sexto años. 
olmeca y tarasca, omitiendo a los indígenas norteños, ${ }^{23}$ que a los ojos de los académicos (antropólogos, arqueólogos e historiadores) e instituciones educativas no representaban un pasado digno frente al mundo mestizo culto. Asimismo, se analiza la Monografía del estado de Guanajuato (1982) como la primera edición del libro Guanajuato. Historia y geografía (1996) para tercer año, pues contienen los discursos oficiales que han dibujado a los indígenas, en general, y que representan a los chichimecas como nómadas y guerreros bárbaros.

Lo que se busca en el análisis de la práctica de la enseñanza de la historia a nivel primaria es ver cómo y por qué se ha mantenido el modelo de la evolución, a pesar que secciona y parcela el entendimiento de las prácticas culturales y sociales de los indígenas -desde el enfoque histórico-. En este sentido, Franz Boas, en el curso de antropología ofrecido en la Universidad Nacional de México en 1912, indicaba que el "método de la evolución se funda esencialmente sobre la observación de la uniformidad de los rasgos culturales en todo el mundo". ${ }^{24}$ No explican más estas líneas de Boas: la antropología de inicios del siglo $\mathrm{xx}$, con su evolucionismo, únicamente había explicado la generalidad y no las particularidades de los indígenas chichimecas -y esto permanece en el siglo XXI.

Este análisis busca mostrar tres procesos históricos de las posturas ideológicas que construyen a los otros-chichimecas- en el discurso oficialista de los libros de texto gratuitos. La propuesta es exponer la ideología de la política pública educativa en tres etapas parcelarias en cuanto a la forma de enseñar la materia de historia de México: a) primeros pobladores; b) culturas de Mesoamérica y Aridoamérica; c) Conquista y la Nueva España. En esos temas hallaremos la "historia de los acontecimientos" que nos permite analizar la imagen del indígena chichimeca de Aridoamérica,

23 En la historiografía arqueológica del siglo xx se considera como "indígenas norteños" a los que habitaban en la gran Aridoamérica, lo dicho equivalía a pueblos nómadas, sin "cultura", entre ellos se ha clasificado a los chichimecas, que dominaban los actuales estados de Querétaro, Guanajuato, Zacatecas, San Luis Potosí, Aguascalientes y parte de Durango. Hoy siguen existiendo indígenas en: Baja California Norte (cochimi, cucapá, kiliwa, kumiai, paipai); Sonora (guarijíos, mayos, pápagos, pimas, seris, tarahumaras, yaquis); Chihuahua (guarijíos, pimas, tarahumaras, tepehuanos); Coahuila (kikapu); Sinaloa (mayos); Durango (huicholes, mexicaneros, nahuas, tarahumaras, tepehuanos). Datos tomados del Atlas de los pueblos indigenas de México, CDI: 2014.

24 Boas, Curso de antropología cultural, p. 12. 
buscando entender cómo el discurso construye la idea de civilización con el objetivo de presentar las culturas de Mesoamérica como las únicas avanzadas y cultas, invención hecha para la sociedad que vivía el sueño de la modernización -en el siglo XX-. Para este cometido se requiere aceptar la identidad mestiza para integrarse al mundo a través de los instrumentos que ha creado la SEP.

Jaime Torres Bodet, titular de la SEP en 1962, en el discurso de apertura del Museo Nacional de Antropología, refleja este anhelo -de ser parte de la modernización-imperante en los ideales del siglo xx:

Sangre de España corre también por las venas de millones de Mexicanos. Es fuerza, en nosotros, el mestizaje. Avanzamos por la afirmación de lo nacional, hacia la integración de lo universal. Nuestra vocación no se encuentra desfigurada por prejuicios étnicos o geográficos. América es nuestro ámbito natural; México la razón de nuestro destino. Pero el escenario de ese destino lo construye la tierra entera. Y queremos participar con independencia en el progreso común de la humanidad. ${ }^{25}$

Descubrir o "redescubrir" a los otros ha sido el ejercicio de asimilación e integración por excelencia del siglo pasado, construyendo andamios justos para los mestizos y no para los indígenas. La SEP, con el disfraz de "asimilación", le dio continuidad al discurso decimonónico y de los gobiernos gestados con la ideología de la Revolución mexicana: civilidad y barbarismo reconfiguran el imaginario histórico indígena creado por la institución educativa que, a su vez, la proyecta en el discurso oficial de sus libros de texto como permanente e inamovible -sin llegar al presente de los indígenas-. Para la SEP, los indígenas norteños (los chichimecas) están muertos y como si fueran una "cosa" los considera extintos; así es como se construye esta premisa; lo que motiva a reflexionar: ¿por qué mantienen este discurso y cómo ha permanecido la imagen de los indígenas chichimecas excluyente de la realidad de la idea de nación mestiza?, ¿por qué -aun en Guanajuato-, los chichimecas siguen siendo los bárbaros, los guerreros, los malos y los ariscos, para la población e instituciones públicas, culturales y educativas?

25 Torres Bodet, "Discurso", pp. 12-13. 


\section{Muertos en el discurso, vivos los chichimecas}

\section{a) Las grandes civilizaciones sedentarias y grupos salvajes nómadas}

Para mostrar los supuestos de este trabajo sobre el discurso institucional de la SEP respecto a la imagen del chichimeca (pensada para el mestizo), expondremos cómo, desde 1960, se busca resaltar en los libros de texto gratuitos de historia a los héroes nacionales (de la Independencia -siglo XIX- y Revolución -siglo xx- y el origen mestizo del mexicano). En este camino los indígenas serán vistos como sometidos y explotados, pese a que existieron protagonistas y héroes indígenas que nos dieron identidad, pero sólo aquéllos de la cultura azteca o mexica, pues no existe otra relevante en dichos libros. Esta concepción se aprendía desde el curso de tercer año de primaria en la asignatura de historia y civismo; en 1960 iniciará el proceso de excluir -oficialmente- de la historia nacional a los indígenas nómadas y/o seminómadas, con el argumento de crear o formar una identidad mexicana a partir de los indígenas civilizados y los indígenas oprimidos "actuales". Esta identidad "centralista" estaba ceñida a la cultura azteca, de la cual se explicaba, desde la fundación de Tenochtitlan, lo que hoy conocemos como la ciudad de México, destacando al poeta Netzahualcóyotl y al último rey, Cuauhtémoc, como personajes que merecían ser considerados representantes de la civilidad prehispánica.

Mi libro de tercer año. Historia y civismo (1964) da muestra de cómo se desdibujó la presencia de los chichimecas frente a otras culturas prehispánicas o mesoamericanas, con la intención de crear el glorioso perfil indígena ad hoc al progreso y modernización del siglo xx. La enseñanza de la historia prehispánica comienza con la lección "Primeros pobladores de México", que inicia la asimilación del concepto "salvaje" con la referencia y los calificativos de "bárbaros" y adoradores del Sol para aquellos habitantes (los primeros pobladores de México); el apartado se limita a mostrar imágenes de hombres desnudos viviendo en cuevas, y a describir su forma de vida:

Eso quiere decir que aquellas gentes vivían en cuevas, que pasaban las noches en las ramas de los árboles. Además no tenían domicilio fijo, sino que constantemente 
iban de un lugar a otro en busca de su alimento; es decir, eran nómadas. Unos comían carne cruda: de venado, de guajolote, etc. [...] Hacían sus vestidos con hojas de plantas o con las pieles de los animales que cazaban. Adoraban como dioses al Sol y ciertos fenómenos de la Naturaleza. ${ }^{26}$

Descripciones semejantes sobre las prácticas sociales de los chichimecas se encuentran en el mismo texto, al punto de hacer creer que términos como "primeros pobladores" y "chichimecas" significan lo mismo que "salvajes" o "bárbaros"; no se logra comprender una diferencia conceptual, porque aparentemente son los mismos. ${ }^{27}$

El siguiente tema del libro, "Descubrimientos trascendentales", no brinda explicaciones de los procesos históricos de los pobladores e indígenas chichimecas que deciden seguir en el nomadismo; simplemente, todos se convierten en sedentarios porque la acción y el descubrimiento de la agricultura y el maíz hicieron posible tal hecho; de esta manera se cierra la posibilidad de pensar que otros pobladores vivían o podían vivir siendo nómadas, porque el argumento es que: "Este fue en verdad un hecho de grandes consecuencias, pues la siembra, el cultivo y la cosecha del maíz, obligándolos a pasar muchos meses en un mismo sitio, hizo que dejaran de ser nómadas". ${ }^{28}$

Entonces, ¿cómo se explicó a los niños que el descubrimiento de la agricultura no hizo que todos los indígenas vivieran en el sedentarismo? El nomadismo es visto como un modo de vida sólo para salvajes y humanos atrasados, el cual el hombre civilizado dejó atrás, es decir, dejó de existir. Aquí la idea del indio nómada es para recalcar que está "extinto", que las

26 SEP, Mi libro de tercer año. Historia y civismo, pp. 24-25.

27 Esto permite pensar que este texto y los siguientes, editados en 30 años por la SEP, empleaban la propuesta de 1943 de Paul Kirchhoff en la que define a: "[...] la frontera norte de Mesoamérica, se distinguió de la frontera sur por un grado mucho mayor de movilidad e inseguridad, alternando en ella épocas de expansión hacia el norte con otras de retracción hacia el sur. Estas últimas se deben en parte a invasiones de grupos de cultura más baja situados al norte de Mesoamérica, [...] Mesoamérica es el último eslabón hacia el norte en la cadena de los cultivadores superiores [...] el resto de esta frontera sus vecinos eran cultivadores inferiores (los jicaque y paya y los sumo y misquito). En la frontera norte la situación era aún más desfavorable, [...], Mesoamérica colindaba directamente con recolectores-cazadores", pp. 6-7; sin duda una descripción y la representación visual de Mesoamérica que dio pauta para imaginarnos "eternamente" a Mesoamérica y Aridoamérica.

28 SEP, Mi libro de tercer año. Historia y civismo, p. 26. 
grandes civilizaciones sólo podían aspirar a la evolución cultural a través del sedentarismo y lo que esto implicaba: agricultura-economía, religión, organización social, ciencia e infraestructura.

Estos conceptos se replican en Mi cuaderno de trabajo de tercer año. Lengua nacional, historia y civismo (1971). Los ejercicios no reflexionan el nomadismo, pero sí revisan el origen de la palabra "chichimeca" (cuyo significado es "bárbaros") y su llegada al valle de México, dejando en claro que la migración de indígenas chichimecas fue generalizada y que todos los indígenas norteños se civilizaron al entrar en contacto con los pueblos sedentarios de Mesoamérica. Por otro lado, tenemos a la cultura azteca o mexica, elegida para explicar "nuestro pasado indígena": modelo de lo que todo mexicano debe entender como civilización prehispánica; con este sentido los ejercicios se ocupan de reafirmar costumbres, educación, vestimenta, religión, organización social y política, además de engrandecer la leyenda o mito de la llegada al valle de México. Además del imperio azteca tenemos a los olmecas y mayas, destacados por sus avances en la arquitectura y la ciencia.

Disolver su continuidad en la vida mesoamericana se reafirma en el apartado "Los chichimecas". La reflexión respecto a estos indígenas es ambigua, pues se retoman las observaciones del apartado "Los primeros pobladores de México”, que los presentan como bárbaros, pero añadiéndoles una característica: eran destructivos. La vaguedad de quiénes eran -y son-, los chichimecas permite escudriñar en ese ideal y eliminar lo que va en contra del esquema del indio civilizado prehispánico. La imagen representativa abarca media cuartilla e ilustra lo que sigue vivo y se percibe en el imaginario colectivo; representa la frontera entre lo aceptable y lo olvidado (véase imagen 1), la línea entre lo arcaico y lo civilizado. 


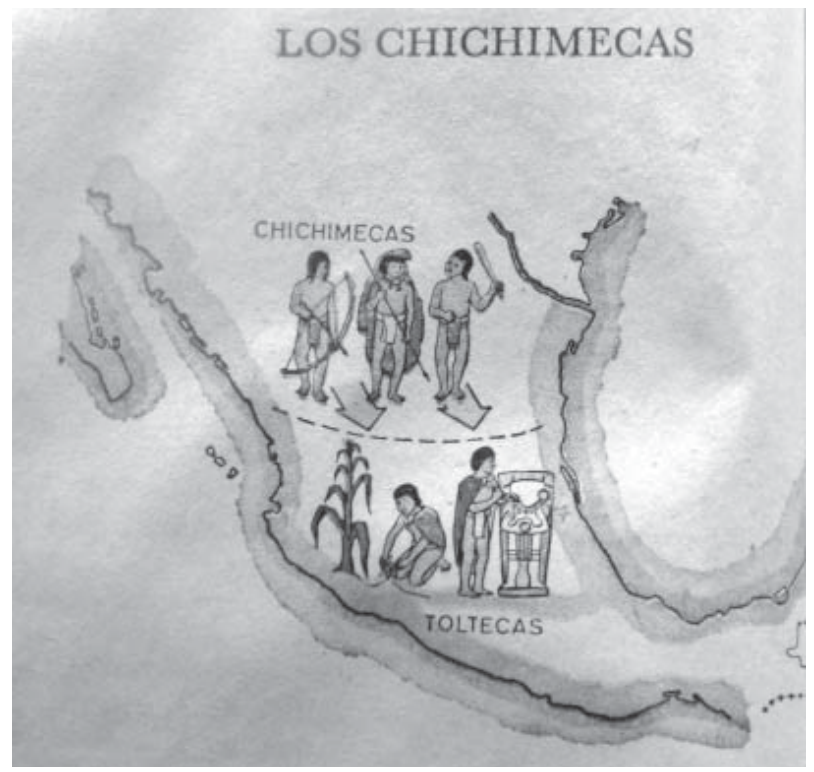

Imagen 1. Los chichimecas.

Fuente: SEP, Mi libro de tercer año. Historia y civismo, 1964. Archivo Histórico del Estado de Guanajuato, Colección Salceda, 3035.

La imagen de los chichimecas representa el discurso oficial del Estado diseñado a través de la SEP. Como bien menciona Peter Burke: "la imagen es la persuasión y la manera de educar al espectador"; 29 es imborrable la huella que deja la observación en la memoria. En este sentido, se representa lo que se ha dejado atrás, el trofeo del progreso elimina lo que fuimos y reconstruye, dota al mestizo de un pasado con prestigio indígena, una sola lengua: el castellano; y una herencia: la nación mexicana mestiza. Podemos entender, entonces, por qué el indígena chichimeca sigue siendo representado en la actualidad con taparrabo, arco y flecha, es decir, sigue vigente el prototipo de bárbaro, a pesar de su extinción imaginaria. La cuestión visual se construye con el discurso escrito y es aquí donde se entrecruzan el pensamiento de la conquista y el del siglo xIx, dibujando el pasado "incómodo" y el presente progresista de la cultura mestiza en el naciente siglo xx:

29 Burke, Visto y no visto..., p. 17. 
Los Chichimecas. Su nombre significa bárbaro. Procedían del norte. Guiados por Xólotl, uno de sus jefes, penetraron en el territorio de los Toltecas y destruyeron cuanto les salió al paso. Pero a poco de vivir entre vencidos Toltecas advirtieron las cosas buenas que éstos hacían y los cautivó aquel modo. Aprendieron a cultivar la tierra, se vistieron con telas de algodón, se dedicaron a las ciencias y las artes. Es decir, que poco a poco salieron de su barbarie y se civilizaron..$^{30}$

Es una constante en los libros de textos de historia afirmar que sólo se puede designar con el título de cultura a las florecidas en el territorio de Mesoamérica, o a los grupos humanos que se convirtieron en sedentarios y, que así, se civilizaron. En este sentido, cultura es sinónimo de sedentarismo, por tanto, no sólo el discurso visual y escrito tiene el objetivo de crear un pasado "civilizado", además hay niveles de valor entre las culturas indígenas: en los libros se explica que la cultura olmeca fue la cultura madre de la civilización mesoamericana; los mayas fueron grandes arquitectos, originaron el concepto numérico del cero; pero, sin duda, son los aztecas o mexicas -los grandes estrategas y dominadores del territorio mesoamericano-, los que nos dieron identidad, pues gracias a sus obras y leyendas tenemos el escudo nacional (del mito de la peregrinación desde Aztlán), incluso el nombre de México viene de ellos y, desde luego, un icono que nos representa: el calendario azteca o piedra del Sol.

Mediante los ejercicios de reafirmación del conocimiento es posible entender por qué existe en los libros de los años sesenta la idea de que hay un antes y un después de los aztecas. En la segunda lección de Mi cuaderno de trabajo de quinto año. Historia y civismo (1964) los ejercicios "Culturas anteriores a la mexica o azteca", están orientados para que el alumno reafirme sus conocimientos mediante actividades sobre los toltecas, las tribus nahuatlacas, la fundación de Tenochtitlan, los aztecas y mayas; por supuesto que las imágenes remarcan "lo civilizado", haciendo un símil con las grandes culturas clásicas occidentales, así como las de Medio Oriente y Oriente; sólo así es comprensible esta recurrencia a las construcciones arquitectónicas majestuosas de aztecas, mayas y toltecas.

30 SEP, Mi libro de tercer año. Historia y civismo, p. 38. 


\section{b) Los chichimecas eliminados}

$\mathrm{Al}$ retomarse las disciplinas sociales y humanas para educar a los niños de fines del siglo Xx, en la década de 1990, reaparece en la portada la imagen de la "Madre Patria" y se reeditan los libros de historia de tercero, cuarto, quinto y sexto de educación primaria con una aparente resignificación de los contenidos históricos.

En lo que atañe a la imagen y discurso del indígena y/o pasado indígena, en el cuarto grado, Mi libro de bistoria de México (1992) se divide en cuatro grandes bloques: a) El México antiguo; b) El México colonial; c) El siglo XIX y d) El siglo Xx. Inicia con Mesoamérica, explicando quiénes fueron los primeros pobladores; sin embargo, este apartado no difiere del todo del imaginario mesoamericano ${ }^{31}$ empleado en la década de los sesenta, pues reafirma que es un gran espacio que se civilizó gracias a la agricultura y a la religión, elementos que ayudaron a mantener unidad a pesar de que el territorio era diverso. De igual manera, persiste la necesidad de validarse frente a otras culturas europeas para adquirir ese nivel de "civilización"; al respecto, se le explica al alumno: "así nació Mesoamérica, una región original que tiene gran riqueza cultural. Sus logros son comparables a los de las civilizaciones antiguas de Mesopotamia, Egipto, China, India y Europa, en el Viejo Mundo". ${ }^{2}$

Con el fin de establecer que Mesoamérica fue un territorio civilizado, hay que hacer un ejercicio comparativo, validar y descalificar aquello que no encaja en la "evolución social", y esto se hace a partir de la idea y

31 Este imaginario sin duda tiene mucho que ver con la propuesta de Paul Kirchhoff en su obra Mesoamérica. Sus limites geográficos, composición étnica y caracteres culturales, publicada en 1943, donde establece cuales son las características culturales que hicieron a Mesoamérica un gran espacio cultural; la discusión de Kirchhoff es una crítica hacía las "viejas" caracterizaciones que se le hacía al territorio mexicano y centroamericano como una gran "masa" geográfica homogénea atrapada entre Norteamérica y Sudamérica, de allí su interés por reconstruir y caracterizar qué era México y Centroamérica: "Por otro lado, las culturas restantes de Centroamérica y México, con excepción del norte de México, no ostentan de ninguna manera caracteres 'norteamericanos', sino que, por el contrario, tal vez tienen más en común con ciertas culturas de Sudamérica que con cualquiera de Norteamérica", p. 2. Esta concepción se encaminó a través de los años a crear una frontera infranqueable entre lo civilizado y lo bárbaro, y hasta hoy en el imaginario colectivo se cree que son antagónicas en todos sus sentidos geográficos, sociales y culturales Mesoamérica y aquello que se llamó el norte de México.

32 sep, Mi libro de bistoria de México, cuarto grado, p. 6. 
palabra "chichimeca" que define la frontera conceptual entre lo sedentariocivilizado y lo nómada-salvaje, ${ }^{33}$ así, se instituye la frontera borrosa e incomprensible para un niño de nueve años que, después de entender que Mesoamérica era civilizada, ¿entonces qué era Aridoamérica? Es aquí donde el discurso reafirma el arquetipo actual de los chichimecas, pintándolos como seres humanos errantes, incapaces de convertirse en sedentarios; por tanto, se recurre a eufemismos para definir Aridoamérica:

Allí vivían pueblos con costumbres distintas a las de los agricultores mesoamericanos. [...] Las tierras secas de Aridoamérica no eran buenas para la agricultura. Sus habitantes se dedicaban principalmente a la cacería y a la recolección de plantas y granos. Se desplazaban continuamente: eran nómadas. Los mesoamericanos los llamaban chichimecas [...] y los mesoamericanos nunca los pudieron dominar..$^{34}$

A finales del siglo xx en los libros de texto se duplicaba el mismo alegato sobre estos indígenas, discurso que ocupa un párrafo y un dibujo de la conquista (sin autor). Podemos entender que a principios del siglo XX sólo se conocían los informes de los españoles del siglo XVI y trabajos de Wigberto Jiménez ${ }^{35}$ que hablan de la guerra chichimeca. En la década de los setenta destaca la publicación de Powell La guerra chichimeca (1550-1600), trabajo descriptivo enfocado en estos territorios "fronterizos". En los ochenta se publican las monografías por estados y la de Guanajuato incluye a los chichimecas; la cuestión es, por qué se sigue recreando esta visión fronteriza como si se desconocieran por completo quiénes eran aquellos indígenas casi vagabundos; por más de treinta años encontraremos este antagonismo: Aridoamérica versus Mesoamérica en los libros de texto y la misma o análoga definición eurocentrista de la cultura: lo que está fuera del concepto de civilización seguirá siendo desconocido o será eliminado.

33 La representación de la frontera mesoamericana está cargada de la noción de modernidad. Desde el punto de vista de Mónica Blanco estos conceptos son el reflejo de los empleados en la década de los cuarenta del siglo xx en el ámbito académico y en el político; pero dejar atrás la palabra "prehispánico" por "Mesoamérica" no tiene ningún sentido de fondo, siguen definiéndose de manera semejante. Blanco et al., Breve historia de Guanajuato.

34 SEP, Mi libro de historia de México, cuarto grado, p. 7.

35 Véase de este autor, por ejemplo, "La colonización y evangelización de Guanajuato en el siglo XVI". 
La manera como define la SEP a los primeros pobladores es prácticamente la misma desde la década de los sesenta: "Los primeros pobladores de América eran pequeños grupos de hombres dedicados a la caza y a la recolección de plantas y semillas [...] estos grupos se desplazaban continuamente, según las estaciones del año y siguiendo a los animales que cazaban". ${ }^{36}$ No existe un proceso histórico lógico, sino contradicciones de la actividad humana en América: si los primeros pobladores llegaron a América alrededor de 40000 a. de C. y la migración concluyó en 8000 a. de C., si se inicia la agricultura en 7000 a. de C. y las grandes civilizaciones de Mesoamérica florecieron en 1500 a. de C., ¿ंen todo ese tiempo los chichimecas fueron estáticos?, ¿eran los mismos pobladores del año 40000 a. de C.? Pareciera que sí. De acuerdo con los conceptos y las imágenes usadas para ilustrar el proceso de la llegada de los primeros pobladores al Continente Americano, éstos y los chichimecas son equivalentes.

El tema "Los pueblos mesoamericanos" es la explicación de las culturas olmeca, maya, zapoteca y mixteca, y se incluye "El occidente", ${ }^{37}$ pero se advierte que esta cultura no construyó grandes ciudades, aunque sí eran hábiles artesanos; se refiere a los tarascos a los que define como "bravos guerreros. El poderoso imperio Mexica nunca los pudo dominar". ${ }^{38}$ Estas pequeñas frases son las que desdibujan la presencia chichimeca; efímeras y efectivas líneas que describen qué eran y su naturaleza primitiva: "Los agricultores de Mesoamérica no pudieron detener a los chichimecas, recolectores y cazadores del norte. Hubo un gran movimiento de pueblos, inestabilidad y guerras". ${ }^{39}$

La década de los noventa se caracteriza -en cuestiones educativaspor la ideología de la diversidad cultural. En el apartado "La herencia del México antiguo", ese pasado se explica como interrumpido por la llegada de los españoles. La creencia de que existió un México antes de la Colonia sigue vigente, tanto, que la SEP pretende inculcar que la herencia del

36 En los estados de Sinaloa, Jalisco, Colima, Nayarit, Michoacán y Guerrero se desarrolló una cultura que no construyó grandes ciudades, pero que elaboró objetos de cobre". SEP, $M i$ libro de historia de México, cuarto grado, p. 11.

37 "En los estados de Sinaloa, Jalisco, Colima, Nayarit, Michoacán y Guerrero se desarrolló una cultura que no construyó grandes ciudades, pero que elaboró objetos de cobre". SEP, $M i$ libro de historia de México, cuarto grado, p. 11.

38 SEP, Mi libro de bistoria de México, cuarto grado, p. 11.

39 Ibid., p. 13. 
indígena culto, civilizado, quedó vacía porque fue "destruida y sólo la cultura campesina sobrevivió [...] los rasgos más refinados de la cultura antigua fueron destruidas". ${ }^{40}$ De acuerdo con los citados libros, lo único que persiste es la lengua y costumbres, ¡como si fuera poca o insignificante cosa en relación con todo lo que se exterminó! A pesar de esa desgracia "histórica", al alumno se le indica o instruye a aceptar que la lengua y las costumbres son una herencia cultural perteneciente a todos los mexicanos -discurso que convierte en "cosa" a los indígenas-; lecciones que se apartan del propósito de enseñar a los alumnos indígenas, que también son humanos y mexicanos.

La herencia "ilustrada" de México es la astronomía y el calendario de los aztecas; la escritura, la arquitectura, la agricultura, la gastronomía, la botánica y la medicina -herbolaria- de los mayas; entre estos elementos materiales e inmateriales están los indígenas actuales, que se ven en el tema "Los indios actuales", pero cuyo contenido excluye a quienes sí existen. La explicación se reduce a decir que "Los indios de México hablan unas $56^{41}$ lenguas antiguas: náhuatl, maya, mazahua, otomí, totonaca, zapoteco, huichol, mayo, y tarahumara, entre otras". ${ }^{42}$ Es decir, reduce el bagaje de los indígenas al uso de una lengua y a "que conservan un fuerte sentido comunitario". ${ }^{43}$ ¿Esto representa la diversidad indígena actual? No expresa mucho este breve apartado -casi nada en realidad-, de los chichimecas y los indígenas en general, más bien niega que existan.

Otro de los temas cuyo manejo nos interesó mostrar es cómo se recurre a explicar la conquista de los chichimecas, resaltando las matanzas de los españoles en tierras indias; en pocas palabras: "En el norte, en cambio, los chichimecas no conocían la sumisión. Lo inhóspito de sus tierras y su habilidad de cazadores y recolectores retrasó su conquista hasta comienzos del siglo xx"; ${ }^{44}$ entonces se concluye que estos indígenas fueron conquistados en el siglo xx por error o negligencia; siendo herederos del México antiguo,

40 Ibid., pp. 16-17.

41 Según el Instituto Nacional de Lenguas Indígenas (2008), son 68 grupos de lenguas indígenas, pero en la tercera edición del libro de historia de cuarto de primaria (2007), se mencionan sólo 59 lenguas indígenas.

42 SEP, Mi libro de bistoria de México, cuarto grado, p. 19.

43 Idem.

44 Ibid., p. 26. 
es de suponer que los indígenas chichimecas son mexicanos y parte del pasado antiguo y del presente de México, ¿̇o entonces qué son?, ¿quiénes son estos indígenas para la sociedad mestiza mexicana? A lo largo de los temas expuestos sobre indígenas o Mesoamérica nunca los chichimecas tendrán un espacio de definición o explicación de sus prácticas socioculturales; la historia oficial dice de ellos sólo que fueron simplemente un manojo de primitivos e involucionados que se dedicaban a cazar, adorar al Sol, al viento, y a matar; la expiación es un presente brumoso y extinto de los que no representan el "México antiguo" para la educación laica y gratuita.

Estos conceptos se reafirman en Mi libro de historia de México de quinto y sexto grados, también de 1992. Los contenidos son los mismos, sin modificación de temas, es decir, en cuarto año se inician los conceptos de civilización, herencia del México antiguo, idea selectiva que seguirá fomentando como cultura a la olmeca, la maya y la azteca, agregando a los zapotecas y tarascos. En los libros de sexto, Aridoamérica sigue siendo vista como un territorio incivilizado, que fue habitado por pueblos con formas de vida muy distintas a las de los civilizados agricultores mesoamericanos, pues muy pocas tierras de Aridoamérica eran buenas para la agricultura. Y se suma otra idea: "No tenían grandes ciudades. Se desplazaban continuamente: eran nómadas. Pero tenían poblaciones y algunos conocían la agricultura". ${ }^{45}$ Sigue vigente la concepción de su bravura, y concluye el párrafo diciendo que "eran excelente guerreros y los mesoamericanos nunca los pudieron dominar". "Además, lo que veremos como "ilustración" no son los chichimecas, parecidos a los primeros pobladores, ni un dibujo de la conquista, sino una fotografía de un conjunto de montañas haciendo alusión a Aridoamérica, pero, ¿qué significa una imagen geográfica sin humanos en un tema cultural? En el mensaje visual, los habitantes de esas tierras han desaparecido.

Es necesario apuntar, además, que la frontera entre Mesoamérica y Aridoamérica se modifica en 1992; en los textos de los sesenta, la frontera se ubica debajo de lo que hoy conocemos como el estado de Guanajuato, y se ha ido recorriendo a la par que diversas investigaciones arqueológicas e

45 Ibid., p.11.

$46 \mathrm{Idem}$. 
históricas han descubierto zonas arqueológicas en los estados de Zacatecas, Guanajuato, San Luis Potosí, Jalisco, lo cual movió la línea imaginaria de la frontera. La SEP establece que la frontera sufre cambios entre los siglos XII y XVI; sin embargo, esa frontera se refiere a cuestiones "civilizadas"; 47 el concepto entre sedentarios y nómadas se queda exactamente igual. Y si se acepta que Mesoamérica no era un territorio único, homogéneo, por qué, entonces, no comprender que los términos "civilizado" y "salvaje" no explican una forma de cultura, no fomentan el entendimiento ni la aceptación de la diversidad entre grupos indígenas, conviviendo en un territorio heterogéneo geográficamente; pero sí crean un pensamiento "evolucionista".

\section{c) Indígenas incómodos en la bistoria de Guanajuato: los chichimecas}

El "nuevo" enfoque de enseñar el pasado, el mundo contemporáneo y el presente de México, abrió las puertas a las ciencias sociales. Los libros de la SEP englobaban el conocimiento social, antropológico, arqueológico e histórico de México, lo que motivó la generación de monografías por entidades federativas en la década de los ochenta, con el fin de enseñar la historia cultural, económica y social de las entidades. En estas monografías se retoma la idea que se empleó en los sesenta de frontera entre Mesoamérica y Aridoamérica; aunque es innegable que a estos conceptos se les dio un toque local y regional.

Para este ejercicio reflexivo tomamos la monografía estatal de 1982 Guanajuato, cerros y bajios, testigos de la historia, ${ }^{48}$ que la SEP tituló "El libro de mi tierra", edición que inició de manera experimental en la entidad. ${ }^{49}$ Este libro se encargó de aclarar el pasado prehispánico del estado; mediante un ejercicio se entiende que en estas tierras no sólo existieron indígenas salvajes que invadían Mesoamérica -y que siglos después mataban

47 La construcción de ciudades -pirámides-e intercambio comercial.

48 Para el caso queretano se editó la monografía: Querétaro anhelos libertarios sobre caprichos geográficos, de 1990, donde se trata el tema de la invasión de los chichimecas, que tan pronto llegaron a estas tierras se hicieron sedentarios, la imagen que muestra a los chichimecas sedentarios es la misma que se utiliza en la página 66 en la monografía de Guanajuato y que explica la construcción de chozas de los nómadas, y no chozas sedentarias.

49 Aunque en 1988 se aceptó y distribuyó con los mismos contenidos de 1982. 
españoles-, sino que las investigaciones arqueológicas realizadas ayudaron a abordar la cultura chupícuaro, calificada como sedentaria, agrícola y con actividades culturales que la hacen parte de Mesoamérica. Esto se le advierte al niño desde el bloque 2, "Las culturas prehispánicas", del subtema "Los pueblos agricultores": "Guanajuato perteneció a Mesoamérica, en tanto que participó, si no de todos los elementos culturales, sí de algunos". ${ }^{50}$

Es importante destacar que hay un pasado indígena civilizado y eliminar la idea de que Guanajuato fue una región de salvajes, porque en el contexto nacional Guanajuato aparecía en el mapa prehispánico como una región nómada; en este contexto, era necesario puntualizar que había sido también Mesoamérica. Asimismo, se establece que los indígenas de origen toltecachichimeca que irrumpieron en el altiplano entre el año 650 y el 900 (véase imagen 2) eran "pueblos procedentes del norte de Jalisco y sur de Zacatecas" y no de Guanajuato. ${ }^{51}$

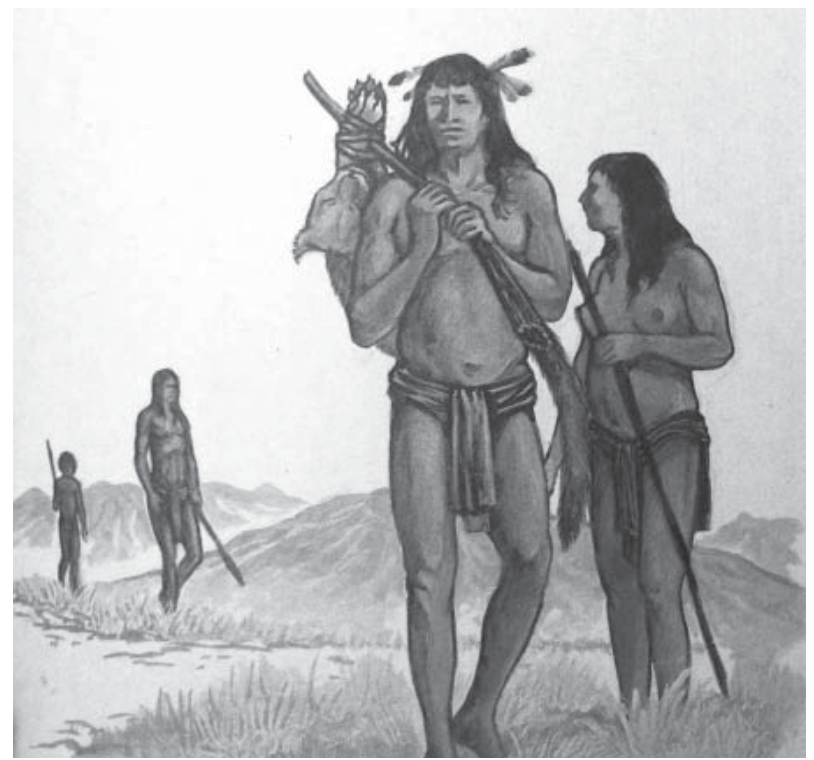

Imagen 2. Grupos nómadas chichimecas.

Fuente: Salceda López, Eduardo, Guanajuato, cerros y bajios, testigos de la historia, p. 49. Biblioteca del Archivo Histórico de la Universidad de Guanajuato.

50 Salceda López, Guanajuato, cerros y bajios, testigos de la bistoria, p. 42.

51 Ibid., p. 49. 
La mención de los indígenas chichimecas se reduce a esa visión periférica de Mesoamérica: los que habitaban al final de la gente civilizada. Por tanto, la construcción de la imagen chichimeca va en los caminos descriptivos: el indio con fortaleza física, andando con flechas, y el chichimeca rústico y nómada; e indudablemente se observa la construcción del mestizo del Estado mexicano, fomentado por el pensamiento académico nacional y estatal. En síntesis, este texto gratuito monográfico de Guanajuato muestra el prototipo del pensamiento colectivo mestizo del siglo xx, retomando investigaciones de arqueólogos, antropólogos e historiadores, que a su vez, recurrieron a las crónicas de los españoles para explicar quiénes eran -y son-, los chichimecas.

El libro causa impacto, no sólo por lo escrito, sino por la construcción visual chichimeca. Las imágenes que le dan vida a la otredad chichimeca prehispánica y colonial van desde el indio rústico (véase imagen 3) al indígena musculoso, guerrero y fuerte.

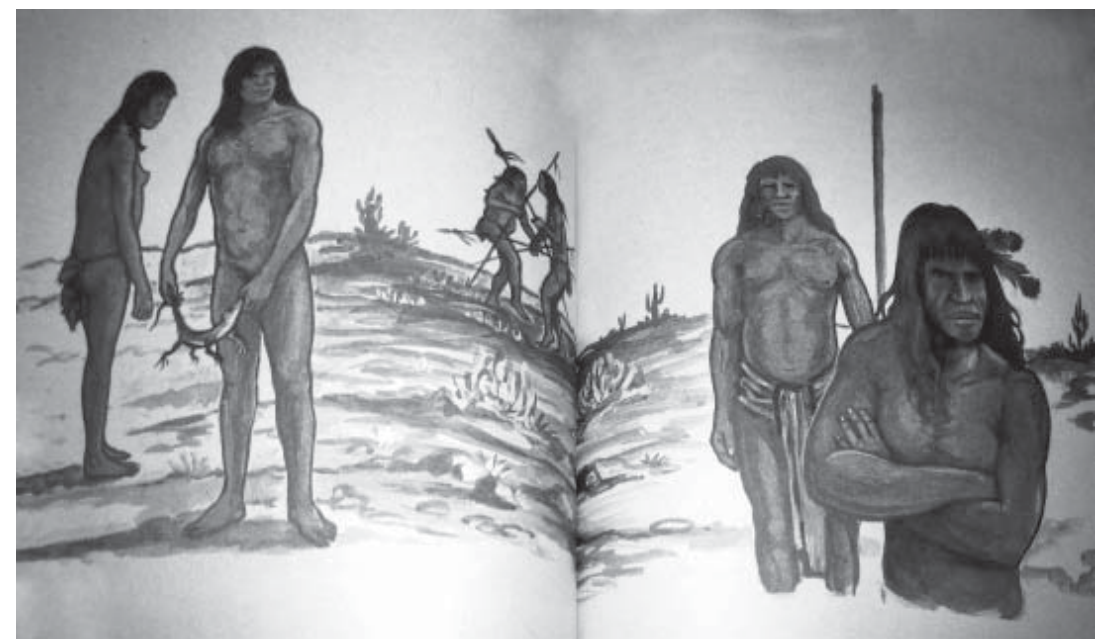

Imagen 3. Representación de indígenas zacatecos y guachichiles chichimecas.

Fuente: Salceda López, Eduardo, Guanajuato, cerros y bajíos, testigos de la historia, pp. 62-64. Biblioteca del Archivo Histórico de la Universidad de Guanajuato.

Al contrario del libro de Historia y civismo, de 1964, éste hace hincapié en la variedad de tribus que existían del genérico chichimeca, porque en esta 
diversidad de bandos o tribus residía la importancia de cuáles de ellos eran los más sanguinarios y los que, en algún momento, pudieron convertirse al sedentarismo: "Entre estos grupos estaban los pames, guamares, guachichiles y zacatecos. ${ }^{52}$ Los guachichiles eran los dueños de la mayor parte de la gran Chichimeca". ${ }^{33} \mathrm{Y}$ aunque suene contradictorio, en esta monografía de la SEP el nomadismo era visto como un modo de vida "que no era improvisado ni desordenado: estaba regulado por la necesidad de obtener alimentos"; ;4 los chichimecas eran conocedores de su entorno y domesticaban la naturaleza.

Es innegable el interés por explicarle al niño el sentido del nomadismo; a esto se puede añadir una crítica a las crónicas españolas sobre cómo los veían a través de sus vestimentas: "Aunque con frecuencia los españoles los describen desnudos, cabe pensar que estos los observaban desde la perspectiva de su propia vestimenta, que -como se sabe- les cubría todo el cuerpo"; ;5 la publicación cuenta con ejercicios reflexivos que no vimos en 1962, ni en las ediciones de 1992 -en libros a nivel nacional-, ni mucho menos en el libro monográfico de 1996, Guanajuato. Historia y geografía. Es breve el párrafo y quizá fugaz este intento de explicar al otro desde la diversidad, pero por lo menos brinda una idea de que los chichimecas son diferentes de como los describieron los otros (los españoles).

Esta monografía pretende exponer quiénes eran estos indígenas. Pese al esfuerzo, se tienen dos problemas en este ejercicio: primero, que la voluntad de entender el nomadismo, no como una condición de atraso sino como un acoplamiento natural de los chichimecas a su espacio, se desvanece ante el impacto de imágenes que los muestran semidesnudos, con rostros duros, musculosos, es decir, recrean también las crónicas españolas (en ocasiones basadas en las descripciones de Powell), ${ }^{56}$ segundo, que es una monografía estatal sin impacto más allá del estado, por lo que aún en el siglo Xxi, sigue

52 Estas referencias se han tomado de Philip W. Powell, de la obra editada por primera vez en 1977, La guerra cbichimeca (1550-1600), Powell hace una interpretación de las crónicas españolas y crea una clasificación de cada tribu y/o nación chichimeca.

53 Salceda López, Guanajuato, cerros y bajios, testigos de la bistoria, p. 61.

54 Ibid., p. 65.

55 Ibid., p. 67.

56 Powell, La guerra cbichimeca (1550-1600). Powell aquí no identifica que Fray Gonzalo de las Casas no es el autor de la Guerra de los chichimecas, sino el agustino fray Guillermo de Santa María. 


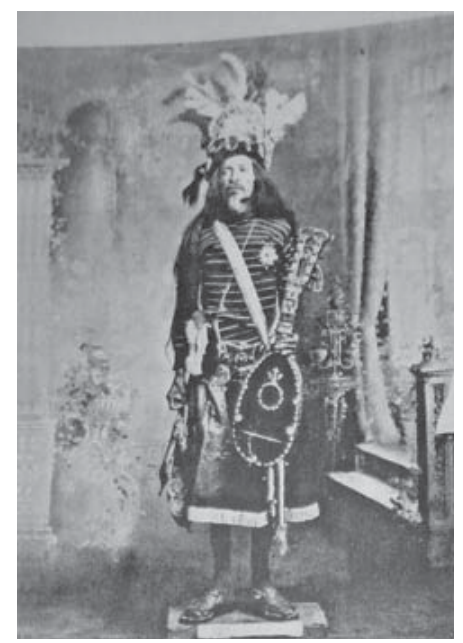

Imagen 4. Conchero.

Fuente: SEP, Guanajuato. Historia y geografía, tercer grado, p. 92.

vigente la imagen de los chichimecas desnudos y salvajes en la memoria mestiza nacional.

Por otro lado, se seguirá sosteniendo que éstos desaparecieron completamente durante la Colonia, cuando el Registro Civil de San Luis de la Paz (después del tratado de paz de la guerra chichimeca, en 1595) inscribió a los chichimecas sobrevivientes (del grupo étnico jonaz) como habitantes de ese municipio, ${ }^{57}$ al noroeste del estado de Guanajuato. El párrafo que hace esta aseveración explica que la condición del nomadismo y la práctica de guerra entre bandos les permitieron sobrevivir a la invasión española, aunque a pesar de esas habilidades: "Durante los periodos de penetración colonial, este cuadro permitió a los chichimecas resistir por más largo tiempo pues no eran un blanco claro. Pero, a la vez, esos rasgos fueron los que finalmente provocaron su aniquilamiento total". ${ }^{58}$

57 “[...] Ellos nombran a este lugar Rancho Úza (rancho indígena) o Misión chichimeca. [...] La congregación Rancho la Misión, reconocida por el Registro Civil de San Luis de la Paz, está dividida en dos partes por la carretera de libramiento a San Luis de la Paz: la Misión de Abajo, al poniente, y la Misión de Arriba, al oriente. Los ézar colindan con lo que fue el territorio otomí de la Sierra Gorda de Guanajuato en el municipio de Tierra Blanca. Hacia el noroeste, separado por esta sierra, se encuentra el grupo pame, en los estados de Querétaro y San Luis Potosí” CDI 2009.

58 Salceda López, Guanajuato, cerros y bajios, testigos de la bistoria, p. 70. 
La monografía de 1996 se divide en dos: "El estado de Guanajuato" y "El pasado de Guanajuato"; en el segundo apartado se aprecia la vigencia de educar bajo el criterio de "civilidad", ya presente en Historia y civismo de 1964. En la segunda parte del tema "Culturas antiguas de Guanajuato"; lección 22, "Los primeros pobladores", "Culturas agrícolas. Purépechas y chichimecas", la temática cultural está desvinculada de los procesos históricos y la construcción de la cultura de los indígenas chichimecas. Se basan en la visión arqueológica, a la que se recurre como fuente de explicación indígena estatal: a) los primeros pobladores nómadas arcaicos, b) la cultura civilizada chupícuaro agrícola sedentaria, y c) los chichimecas nómadas y extintos.

Aunque aparece en la monografía de 1982, en la de 1996 no se explica quiénes eran los chichimecas. Las breves descripciones de las prácticas de sobrevivencia y rituales religiosos, de alguna manera habían construido el imaginario chichimeca que se conoce en el ámbito nacional; sin embargo, -por lo menos en lo escrito- se ve derrumbado al relacionarlos sin ningún criterio histórico o antropológico con los concheros (véase imagen 4), ${ }^{59}$ éstos se perciben totalmente eliminados al mencionar que, además de los chichimecas y de los purépechas, en Guanajuato vivieron los otomíes: "Actualmente los descendientes de los otomíes viven en Guanajuato, Querétaro, San Luis Potosí, Hidalgo y el Estado de México. Se mantienen unidos porque han conservado sus tradiciones y costumbres". ${ }^{60}$ Aquí ya no habrá cabida, ni la intención de explicar que estos nómadas y seminómadas indígenas habitan en el noroeste de su actual estado de Guanajuato, es decir, este grupo muere en letra en este tema o apartado del texto gratuito.

En lo que concierne al imaginario del sometimiento español encontraremos "La guerra de los chichimecas"; hasta el título resulta sugerente porque éste no dice "en contra de los chichimecas". No hay estructura pedagógica entre apartados o temáticas, es decir, los procesos históricos se encuentran fragmentados; se termina la temática prehispánica y se inicia de cero con la "Colonia española". Si bien se mencionó que no había en el Guanajuato contemporáneo chichimecas, sólo otomíes, en el

59 Danzantes mestizos, cuyo origen de ninguna manera es netamente prehispánico, sino que surgen del mestizaje de las prácticas religiosas indígenas y las creencias católicas.

60 Ramírez Gasca, Guanajuato. Historia y geografía, pp. 92-93. 
siguiente apartado se dirá que sí, que "sus descendientes todavía viven en ese municipio actual -San Luis de la Paz-, en un lugar que ellos llaman Rancho Úzua, que quiere decir 'rancho indígena' y se les conoce como grupo chichimeca jonaz". ${ }^{61}$ Una de las explicaciones sobre estos escritos históricos anacrónicos es que a los chichimecas no se les da relevancia alguna en la herencia prehispánica por ser nómadas, pero sí se les ve como el grupo indígena que mantuvo una guerra sangrienta contra los españoles por cincuenta años. Respecto al sometimiento de los chichimecas -siglo XVI-, se afirma: "después de la conquista y la colonización fueron famosos los chichimecas y los cimarrones, que descendían de las montañas para atacar y asaltar poblaciones, caminos y haciendas en protesta porque los españoles invadían sus territorios de caza y para evitar que pudieran someterlos". ${ }^{2} \mathrm{El}$ texto expone que en esta guerra los españoles mataban indígenas y dejaban a unos cuantos con vida para esclavizarlos, pero los indígenas mataban quemando las poblaciones; esta matanza terminó gracias a los "frailes" quienes los convirtieron en sedentarios, un eufemismo para explicar el proceso de la civilización occidental de los chichimecas, porque les ofrecen tierras, alimentos y trabajo. Es posible observar discursos contradictorios en pocas líneas, que son causa de confusión para los niños, pues si se les dice que estos grupos eran nómadas y el nomadismo es visto como "salvajismo", entonces parece que ellos deben entender que la conquista fue "buena" para los indígenas porque los hicieron sedentarios; esto se reafirma con el siguiente párrafo:

Cuando terminó la guerra Chichimeca la economía mejoró, se pudo comerciar con los centros mineros, aumentó la producción de metales, se abrieron minas en San Felipe y la Sierra Gorda, se establecieron nuevos talleres para fabricar telas, zapatos y muebles, mercancías que se comerciaban desde el Bajío. [...] hubo más ganado, más tierras para sembrar, se construyeron caminos, edificios públicos y casa. En resumen, después de la guerra Chichimeca mejoró la economía colonial en su conjunto. ${ }^{63}$

61 Ibid., p. 103.

62 Ibid., p. 102.

63 Ibid., p. 103. 
Es contundente la explicación de esta guerra; con cierto romanticismo se entiende como un proceso necesario para la civilización y modernización de lo que hoy es Guanajuato; conjunto de fases subsecuentes que se deben al avance económico minero y a la sociedad española y criolla, justificándose la muerte de muchos y la "domesticación" de los bárbaros indígenas chichimecas. Sería ingenuo creer que esto no tiene consecuencias en la construcción del imaginario mestizo sobre los indígenas chichimecas; lo cierto es que los jóvenes de la región que hoy tienen entre 23 o 24 años, reproducen estás "creencias" de que los chichimecas eran salvajes "mataespañoles", y que ya no existen.

\section{Conclusión}

La enseñanza de la historia en el nivel básico ha promovido estereotipos que no invitan a niños ni adultos a reflexionar sobre los indígenas chichimecas actuales y los que habitaron ese territorio extenso denominado por la historiografía antropológica, arqueológica e histórica como Aridoamérica. Hay tres temas importantes dentro de los libros de texto de historia (tercero, cuarto, quinto y sexto años de primaria) donde los indígenas chichimecas tienen efímeras apariciones que, sin embargo, han sido determinantes para formarse un juicio de los mexicanos mestizos: a) primeros pobladores de América; b) Mesoamérica y Aridoamérica; c) guerra chichimeca (Conquista y Colonia). En el abordaje del tema de la Conquista, ni siquiera es posible conocer -menos entender- la cultura chichimeca, porque la invasión de los españoles a América se explica sólo a partir de la caída de la gran Tenochtitlan, la mortandad y esclavitud de los indígenas, pero en un contexto general no sabemos qué sucede con los otros grupos indígenas. Se menciona la conquista del norte, que se caracterizó por ser más lenta gracias a su estado social de tribus que "no conocían la sumisión" y cuyas "agrestes tierras y su vida nómada les permitió resistir mejor". ${ }^{4}$ Pero aun en este contexto de dominio y muerte, parece que los chichimecas son "malos": malos para Mesoamérica, malos para la Colonia española, porque una vez sometida

64 SEP, Mi libro de historia de México, sexto grado, p. 39. Esta información es la misma en el libro de Mi libro de historia de México, quinto grado (1992). 
Mesoamérica y llegada la "palabra de Dios", de acuerdo con el libro de texto gratuito de la SEP para quinto y sexto años, ellos siguieron siendo una tribu sanguinaria, por lo que fue una labor "dura" para los jesuitas y franciscanos que "fundaron pueblos y misiones con indios cristianos el atraer a los nómadas. En otras regiones hicieron fortificaciones para defenderse de los indios bravos, como los apaches; a menudo, ya pacificados, los indios se levantaban y destruían pueblos y misiones. No fueron pacificados del todo sino hasta el siglo xx". ${ }^{65}$

Estas últimas líneas son reveladoras porque permean la visión de la Conquista, de quien "investiga y valida”, en este caso la SEP. Entonces, en el imaginario colectivo mestizo, éstos siguen siendo salvajes y brutales. Por tanto, en el niño de edad escolar se está forjando una idea que concuerda con lo aprendido en la escuela pública, ${ }^{66}$ de que los chichimecas no son indígenas de los que deban sentirse orgullosos, sino que se trata de los otros indios -los salvajes- que apenas en pleno siglo xx fueron dominados, ¿pero quién los quería pacíficos, quién los quería dominar en un siglo independiente? La guerra chichimeca del siglo XVI se debió al descubrimiento de oro y plata por los españoles en aquellas tierras consideradas áridas e infértiles, por lo cual urgía desplazarlos del territorio, pero, en el siglo xx ¿por qué pacificar a quienes son también mexicanos?

A través de los libros de texto de historia de la SEP se ha intentado mostrar cómo el tema de los chichimecas en el siglo xx se redujo a fijar la idea de que fueron indígenas salvajes que habitaban en Aridoamérica, enfoque histórico que no ha cambiado en el siglo XxI, pues el texto de Historia de cuarto grado de 2007 afirma: "Los Chichimecas atacaban a los españoles por sorpresa, en terrenos pedregosos donde no pudieran perseguirlos a caballo, iban desnudos y pintarrajeados y lanzaban una lluvia de flechas. Eran muy resistentes; pronto aprendieron a montar. Para pacificarlos, los españoles finalmente tuvieron que ofrecerles, reses, ropa y convencerlos de que vivieran en pueblos". ${ }^{67}$ Esta visión maniquea de indígenas buenos contra indígenas malos, indígenas bárbaros contra españoles civilizados, se ha ido construyendo y reacomodando desde el ámbito académico, imaginario

65 Ibid., p. 39.

$66 \mathrm{Y}$ en la privada, recordemos que las escuelas privadas llevan el mismo currículo de estudio. 67 SEP, Historia, cuarto grado, pp. 57-58. 
colectivo e ideología del Estado mediante las ediciones escolares de la segunda mitad del siglo Xx, visión que continúa en el siglo XXI.

No podemos pensar que la SEP, institución surgida en el siglo xx para ser responsable de la educación de los mexicanos, sea ajena de lo que se crea y recrea en la memoria colectiva. Sin duda, todo el ejercicio de la construcción del otro tiene relación con pensamientos o ideologías surgidas de los procesos de aprendizaje histórico.

Al describir a aquéllos, nosotros y los otros a través de la imagen y lo escrito, los libros de texto gratuitos de la SEP mantienen la separación entre lo civilizado y lo bárbaro, afianzando la imagen del indígena "prieto, chaparrito, semidesnudo", así como la del chichimeca "sanguinario y ratero". Estos libros son la fuente escrita oficial que da continuidad a esas ideas (del Estado hacia la sociedad) y alimenta la visión excluyente del indígena chichimeca.

\section{Bibliografía}

Aguilar, José Antonio et al. Querétaro, anhelos libertarios sobre caprichos geográficos: monografía estatal, México, SEP, 1990.

Amodio, Emanuele, Formas de la alteridad: construcción y difusión de la imagen del indio americano en Europa durante el primer siglo de la conquista de América, Quito, Ecuador, ediciones ABYA-YALA, 1993.

Blanco, Mónica et al., Breve historia de Guanajuato, México, El Colegio de México, Fideicomiso Historia de las Américas, FCE, 2000.

Burke, Peter, Visto y no visto. El uso de la imagen como documento histórico, Barcelona, Crítica, 2001.

Carrillo Cázares, Alberto, "Introducción”, en fray Guillermo de Santa María, Guerra de los chichimecas (México 1575-Zirosto 1580), Zamora, Mich., El Colegio de Michoacán/El Colegio de San Luis/Universidad de Guadalajara, 2003.

Comisión Nacional para el Desarrollo de los Pueblos Indígenas (2014), Atlas de los pueblos indígenas de México en: http://www.cdi.gob.mx/index. php?option $=$ com_wrapper\&view $=$ wrapper\&Itemid $=200027$ 
Comisión Nacional para el Desarrollo de los Pueblos Indígenas (2009), Chichimecas jonaz-ézar en: http://www.cdi.gob.mx/index. php?option $=$ com_content\&view $=$ article\&id $=584$ :Chichimecas-jonazezar\&catid $=54:$ monografias-de-los-pueblos-indigenas\&Itemid $=62$

Conaliteg-SEP (2010), Historia en: http://www.conaliteg.gob.mx/index. $\mathrm{php} /$ historia

Elías, Nobert, El proceso de la civilización: investigaciones sociogenéticas y psicogenéticas, México, FCE, 2009.

Jiménez Moreno, Wigberto, "La colonización y evangelización de Guanajuato en el siglo Xvi", Cuadernos Americanos, núm. 1, ene.-feb., 1944.

Kirchhoff, Paul (1960), "Mesoamérica. Sus límites geográficos, composición étnica y caracteres culturales", en Suplemento de la revista Tlatoani, núm. 3, ENAH, México, D. F., digitalizado [en línea] Xalapa, Ver., AL fin LIEBre EDICIONES DiGITALES. 2009, en: < http://.alfinliebre.blogspot.com/>

Lombardo, Toledano, Vicente (1924), El problema del indio, México, SEPSetentas, 1974.

Pimentel, Francisco, Memoria sobre las causas que han originado la situación actual de la raza indígena de México y medios para remediarla, México, Imprenta de Andrade y Escalante, 1864 [en línea].

Powell, W. Philip, La guerra chichimeca (1550-1600), México, FCE, 1996.

Tomé Martín, Pedro, "Preámbulo: La cuestión de autor a propósito de guerra de los chichimecas", en Fray Guillermo Santa María, Guerra de los chichimecas, México, El Colegio de Michoacán/El Colegio de San Luis/ Universidad de Guadalajara, 2003.

Urías Horcasitas, Beatriz, Historias secretas del racismo en México (1920-1950), México, TusQuets, 2007.

\section{Archivos y bibliotecas}

I. Archivo General del Estado de Guanajuato. Colección Sauceda

Salceda López, Eduardo, Guanajuato, cerros y bajíos, testigos de la historia. Monografía estatal, México, Secretaría Educación Pública, 1988 
Secretaría de Educación Pública, Mi libro de tercer año. Historia y civismo, México, 1964. , Mi libro de cuarto año. Historia y civismo, México, 1971.

, Mi cuaderno de trabajo de cuarto año. Lengua nacional, bistoria y civismo, México, 1971.

\section{Biblioteca Lic. Armando Olivares Carrillo, Universidad de Guanajuato}

Boas, Franz, Sesión de ciencias políticas y jurídicas. Curso de antropología general, México, Universidad Nacional de México, Escuela de Altos Estudios, 1912.

Gamio, Manuel, Forjando patria (pro nacionalismo), México, Librería de Porrúa Hermanos, 1916.

Pimentel, Francisco. "Situación actual de los indios. Remedios", en Jacinto Pimentel, Fernando Pimentel (comps.), Obras completas. Memoria sobre las causas que han originado la situación actual de la raza indígena de México y medios de remediarla, tomo III, México, Tipografía Económica, 1903.

\section{Archivo Histórico de la Universidad de Guanajuato}

Ramírez Gasca, Gustavo, Guanajuato. Historia y geografía. Tercer grado, México, SEP, 1996.

Salceda López, Eduardo, Guanajuato, cerros y bajóos, testigos de la historia. Monografía estatal (edición experimental), México, Secretaría de Educación Pública, 1982.

Secretaría de Educación Pública, Mi libro de bistoria de México, sexto grado, México, 1992. , Historia, cuarto grado, México, 1996. - Historia y civismo, tercer grado, México, 1962. , Mi libro de historia de México, cuarto grado, México, 1992. , Historia, México, 2007. 
IV. Sala de lectura de la Benemérita y Centenaria Escuela Normal Oficial de Guanajuato

Archivo Histórico Lucio Marmolejo, publicaciones periódicas, "Discurso pronunciado por el Dr. Jaime Torres Bodet" en Boletín INAH, SEP, núm. 17, pp. 12-13.

Secretaría de Educación Pública, Mi cuaderno de trabajo de tercer año. Lengua nacional, bistoria y civismo, México, 1960.

, Mi cuaderno de trabajo de quinto año. Historia y civismo, México, 1964.

V. Biblioteca del Departamento de Educación, División de Ciencias Sociales y Humanidades, Universidad de Guanajuato

Secretaría de Educación Pública, Las misiones culturales. Las escuelas normales rurales, México, 1927. 